\title{
Public and private dental services in NSW: a geographic information system analysis of access to care for 7 million Australians
}

\author{
Jenny Willie-Stephens ${ }^{\mathrm{A}}$, Estie Kruger ${ }^{\mathrm{A}, \mathrm{B}}$ \\ and Marc Tennant ${ }^{\mathrm{A}}$ \\ ${ }^{\mathrm{A}}$ International Research Collaborative - Oral Health And Equity, \\ Department of Anatomy, Physiology and Human Biology, \\ The University of Western Australia \\ ${ }^{\mathrm{B}}$ Corresponding author.Email: estie.kruger@uwa.edu.au
}

health services relative to the population they serve. ${ }^{3}$ The spatial dimension of access is a critical issue in health care. Recent studies have used spatial analysis to measure potential accessibility to primary and secondary health services in order to identify geographic inequalities in health care delivery. ${ }^{4,5}$ Australians are one of the healthiest populations in the world, however there is evidence of inequalities and inequities in accessing oral health services. ${ }^{6,7}$

Universal healthcare coverage in Australia excludes dental care; most dental services (80-90\%) are delivered by the private sector on a fee-per-item basis. The public sector exists with varying eligibility criteria, and is mostly directed at children, low-income individuals, pensioners and defined disadvantaged groups. ${ }^{7}$ Despite the reduction in dental decay in children and tooth loss in adults, oral diseases and disorders remain prevalent and are a substantial burden to the Australian population. Poor oral health is evident in Indigenous communities, and amongst low income earners, rural and remote area dwellers, and the elderly; ${ }^{8}$ evidence exists that access to dental care in Australia has a strong socioeconomic dimension, as well as a strong rural-urban dimension. ${ }^{7}$

Against this backdrop, the aim of this study was to investigate the distribution of public and private dental practices in New South Wales (NSW) to test the hypothesis that the distribution of dental practices reflects the geographic, demographic and socioeconomic features of the population and therefore the known gradient of oral disease.

\section{Methods}

This study used a cross-sectional study design. All the data were collected from open access web-based sources; no ethics approval was therefore necessary. Microsoft Excel 2003 was used for database storage.

\section{Public dental practice locations}

The address of each public dental practice in NSW was obtained from government websites. These were crosschecked against the Yellow Pages telephone directory as at June 2011 and entered into the Excel database. The public dental practices mapped in this study were adult service 
practices and Aboriginal Medical Services. The NSW Government operates an integrated child and adult service predominately through shared site facilities (and continues to extend this position). The small number of practices which remain embedded in schools were not included in the sample.

\section{Private dental practice locations}

The address for each private dental practice in NSW was obtained from various sources (e.g. phone books, professional lists, Google maps, web searches) and crosschecked against the Yellow Pages as at June 2011.

\section{Population statistics}

Population data were obtained from the Australian Census of Population and Housing of 2006. ${ }^{9}$ The population data were divided by Census Collection District (CD), defined by geographic boundaries. The geographic boundaries were also obtained from the Australian Bureau of Statistics (ABS) website.

\section{Socioeconomic status}

The Socio-Economic Indexes for Areas (SEIFA) at CD level formed the basis of the measure of socioeconomic disadvantage by geographic areas. SEIFA is a suite of four summary measures that have been created from Census information. ${ }^{10}$ SEIFA values are ranked into deciles. The most disadvantaged $10 \%$ of areas in Australia are given a decile number of one; the second most disadvantaged $10 \%$ of areas are given a decile number of two, and so on up to the least disadvantaged $10 \%$ of areas which are given a decile of $10{ }^{11}$

\section{Outcome measures}

The main outcome measures for this study were the distribution of public and private dental practices in $\mathrm{NSW}$, the distance from CD of residence to these services, and the differences in access to these services for groups of different socioeconomic status. Data were analysed for the Sydney metropolitan area and the rest of NSW (henceforth rural) separately. The primary post office (GPO) of NSW (based in Sydney) was used as a central datum point and metropolitan areas were nominally defined as the area within $50 \mathrm{~km}$ of the GPO. This $50 \mathrm{~km}$ area was chosen as it encompasses most of the densely populated regions of Sydney, but at the same time remains a relatively simple shape for clarity. It also encompasses the various definitions of metropolitan areas that are in use (e.g. the Commonwealth Government's definitions of city vs rural). ${ }^{12}$ Using geographic information system technology, CDs with a centroid outside of $2.5 \mathrm{~km}, 5 \mathrm{~km}$, and $7.5 \mathrm{~km}$ from a public dental practice in the city were identified and further analysed by socioeconomic status. The same was done for private practices in the city, except that CDs with a centroid of $1.0 \mathrm{~km}$ and $2.5 \mathrm{~km}$ were identified and further analysed by socioeconomic status. Different distances were used for public and private practices as the number of public practices is much lower than the number of private practices and thus they have to cover populations distributed across far larger geographical areas than the private practices. CDs with a centroid greater than $12.5 \mathrm{~km}$, $25 \mathrm{~km}$ and $50 \mathrm{~km}$ from a public dental practice for rural NSW were also identified and further analysed by socioeconomic status. All distance classifications were cumulative and not mutually exclusive. Straight-line distances were used as a proxy measure of access. As discussed by Phibbs and Luft, ${ }^{13}$ the correlation between travel time and straight-line distance is high in most cases, lowering for shorter distances and in dense urban areas with high traffic congestion and reliance on surface roads.

No distance or socioeconomic analyses were conducted for the private dental practices in rural NSW as the density of practices was low (out of a total of 3289 private practices, only 683 were distributed across rural NSW). As private practice locations are determined by the market and economic drivers, practices outside of capital metropolitan areas have previously been found to be located in higher population density, large regional centres. ${ }^{14}$ In addition, public dental practices play a strategic role for the wider geographic regions of NSW.

\section{Geocoding}

All dental practices were geocoded using Google maps. The geographic boundary data for each CD were obtained from the ABS. These were integrated with the population and socioeconomic data, and the geocoded practices using ArcGIS (version 9, ESRI, Redlands, California, USA). The geographic measures analysis was also completed using ArcGIS

\section{Results}

The total number of public dental practices that were geocoded in NSW was 170 and the total number of private practices was 3289, of which $2606(80 \%)$ were in city areas. NSW had a total of $11811 \mathrm{CDs}$, representing $10 \%$ of the Australian total land mass, and with a total population of 7.2 million (which represents one-third of Australia's total population). There was an uneven distribution of public and private dental practices across NSW, with a high concentration of both in the city (Figure 1). The majority of public dental practices in the city were located in similar areas as the private dental practices.

\section{Public dental practices}

Public dental practices were widely scattered in rural areas (Figure 1). In population terms, in rural NSW, 2.1 million people lived within $50 \mathrm{~km}$ of a public dental practice; of 

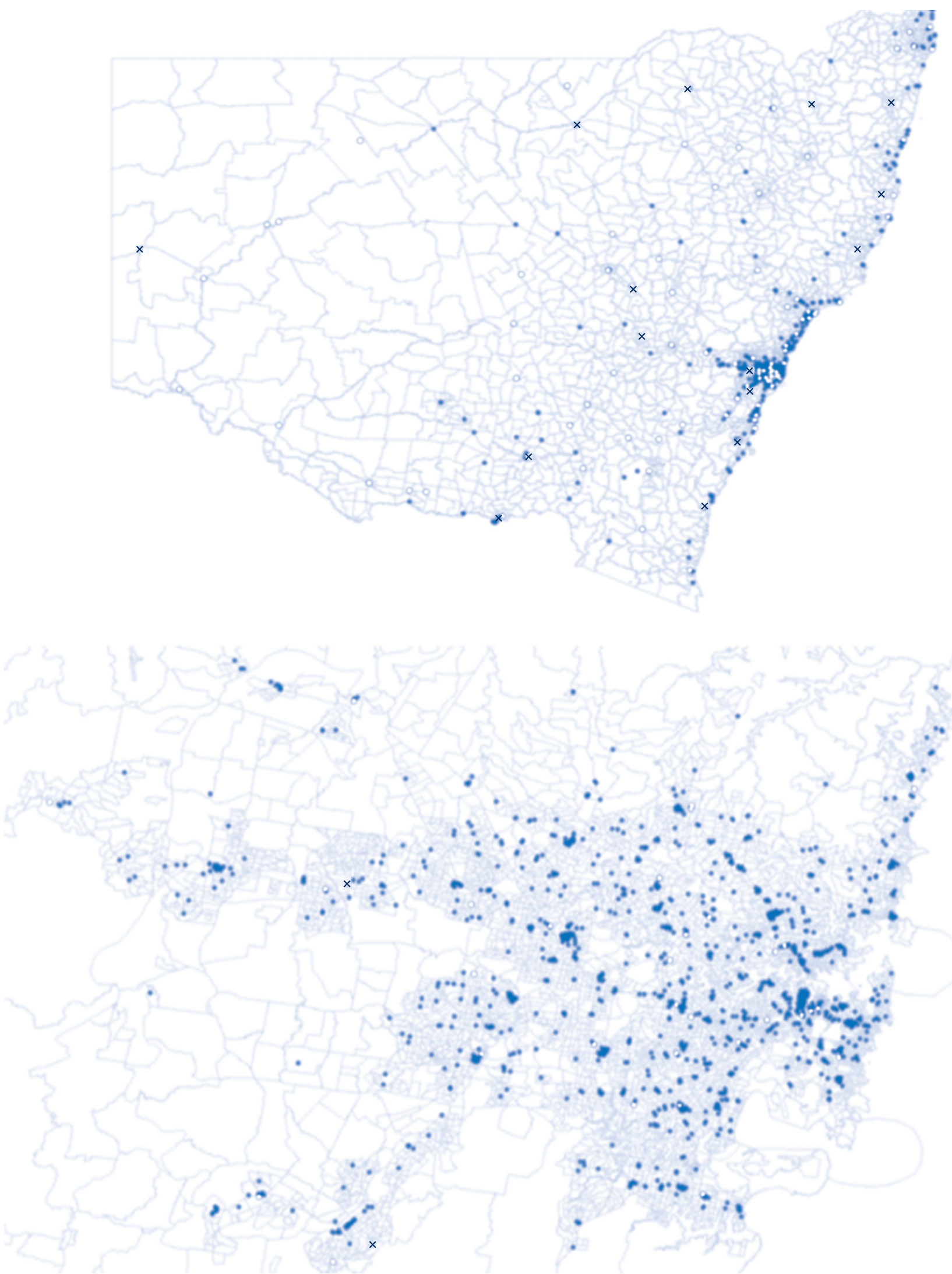

Figure 1. Distribution of public (०), private (๑) and Aboriginal Medical Service (x) based dental practices in NSW (top) and at higher magnification for Sydney (bottom), 2011

these, 1.4 million people lived within $12.5 \mathrm{~km}$. In metropolitan Sydney the number of people who lived within $7.5 \mathrm{~km}$ of a public dental practice was 3.4 million; of these, 1.3 million people lived within $2.5 \mathrm{~km}$.
Twelve percent of the population in the most disadvantaged SEIFA decile lived greater than $50 \mathrm{~km}$ from a public dental practice in rural NSW (Figure 2). SEIFAs 1-6 had $8-12 \%$ of the population living greater than $50 \mathrm{~km}$ from a 


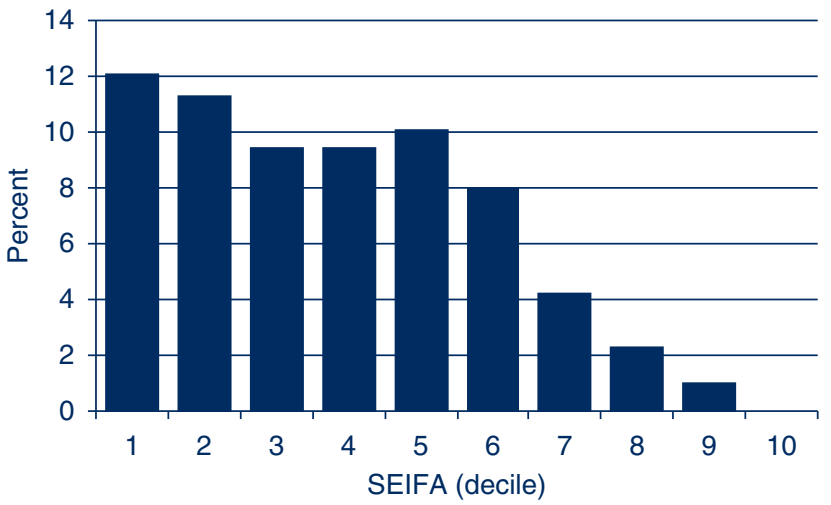

Figure 2. Proportion of people in rural NSW who live greater than $50 \mathrm{~km}$ from a public dental practice, by SEIFA decile, 2011 SEIFA: Socio-Economic Indexes for Areas

Decile 1 is the most disadvantaged $10 \%$ of the population; decile 10 is the most advantaged $10 \%$ of the population.

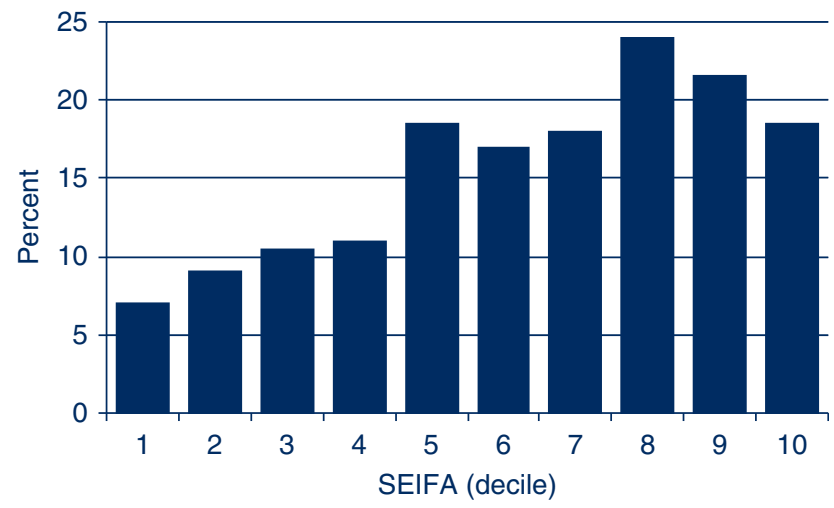

Figure 3. Proportion of people in Sydney, NSW, who live greater than $7.5 \mathrm{~km}$ from a public dental practice, by SEIFA decile, 2011

SEIFA: Socio-Economic Indexes for Areas

Decile 1 is the most disadvantaged $10 \%$ of the population; decile 10 is the most advantaged $10 \%$ of the population.

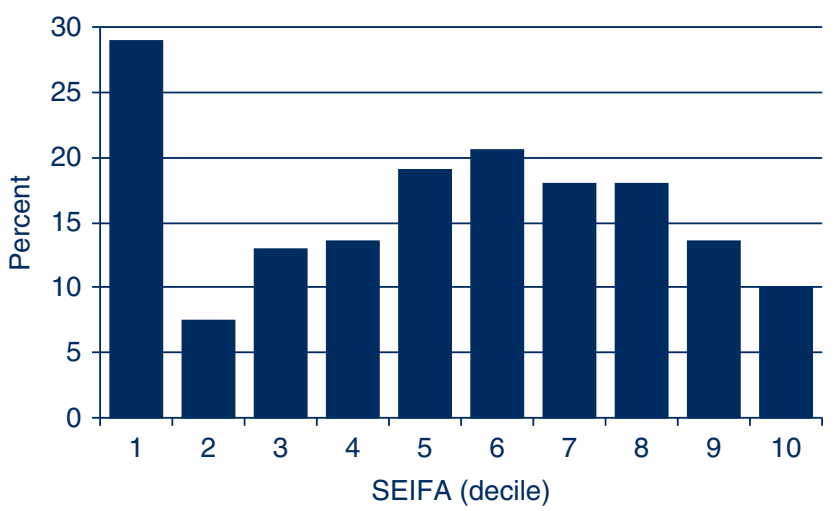

Figure 4. Proportion of people in Sydney, NSW, who live greater than $2.5 \mathrm{~km}$ from a private dental practice, by SEIFA decile, 2011

SEIFA: Socio-Economic Indexes for Areas

Decile 1 is the most disadvantaged $10 \%$ of the population; decile 10 is the most advantaged $10 \%$ of the population.

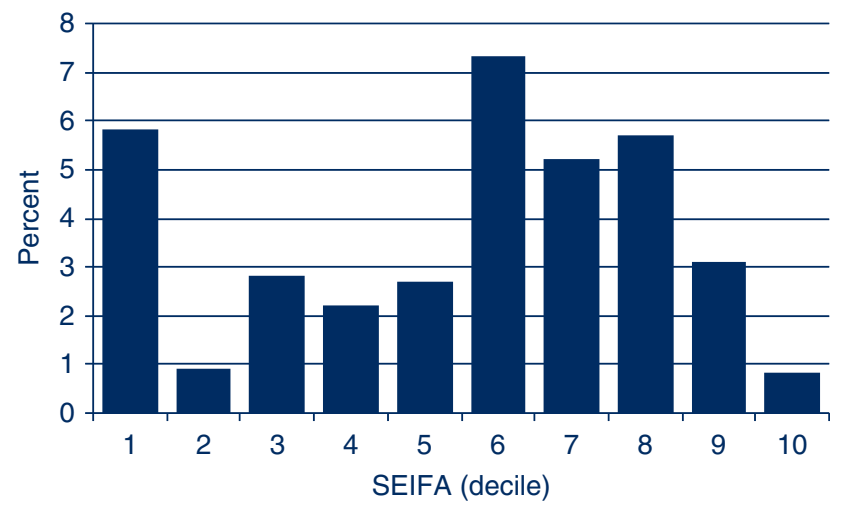

Figure 5. Proportion of people in Sydney, NSW, who live greater than $1 \mathrm{~km}$ from a private dental practice, by SEIFA decile, 2011

SEIFA: Socio-Economic Indexes for Areas

Decile 1 is the most disadvantaged $10 \%$ of the population; decile 10 is the most advantaged $10 \%$ of the population.

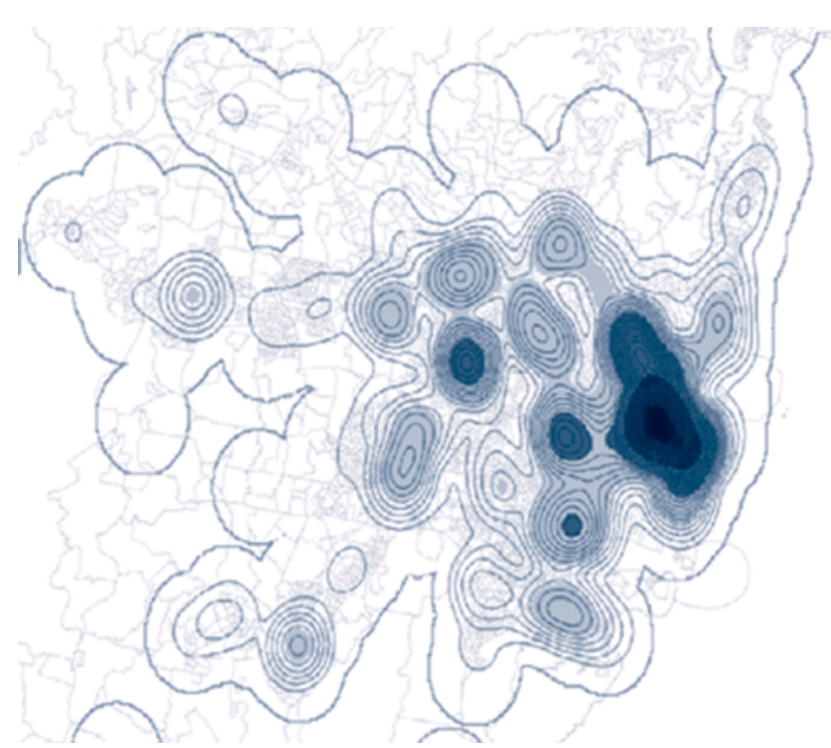

Figure 6. An iso-density map of the number of private dental practices in Sydney, NSW, and surrounding areas (approximately $50 \mathrm{~km}$ ), 2011

Areas highlighted in darker shades have the highest densities.

public dental practice. However, the percentage of the population was low for SEIFA deciles 7-9, and no-one in SEIFA 10 lived more than $50 \mathrm{~km}$ from a public practice.

In the city the reverse was true; $9 \%$ of the three most disadvantaged groups lived greater than $7.5 \mathrm{~km}$ from a public dental practice while the three least disadvantaged SEIFA deciles had a higher percentage (21\%) who lived greater than $7.5 \mathrm{~km}$ from a public dental practice. SEIFAs 1-4 had a lower percentage of the population living greater than $7.5 \mathrm{~km}$ from a public practice than SEIFAs 5-10 (Figure 3). 


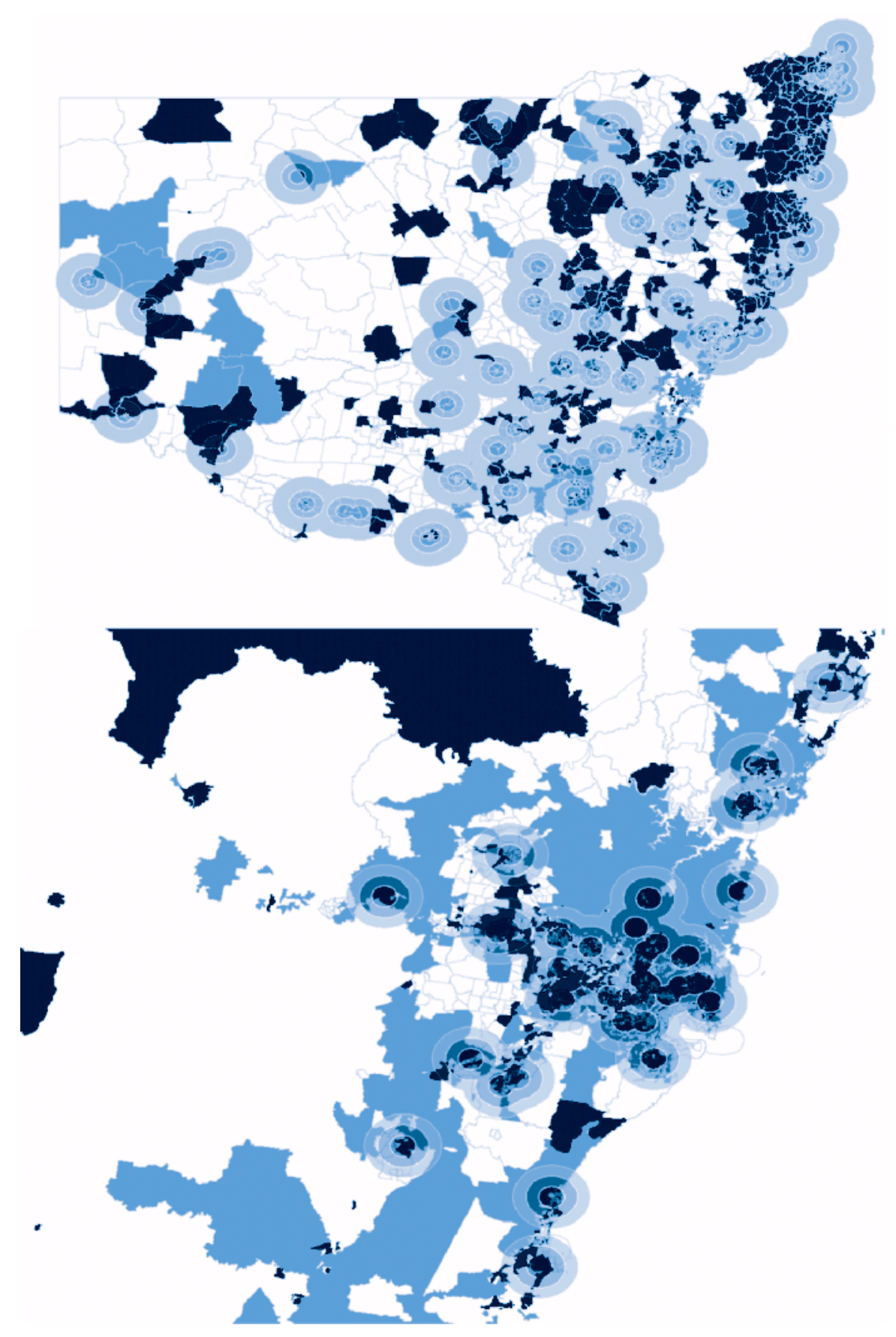

Figure 7. Public dental practices overlaying SEIFA deciles, NSW, 2011

Buffers for rural NSW (top) were 12.5, 25 and $50 \mathrm{~km}$ and were 2.5, 5 and $7.5 \mathrm{~km}$ for metropolitan Sydney (bottom).

Dark blue (deciles 1, 2 and 3; most disadvantaged) and light blue (deciles 8, 9 and 10; least disadvantaged).

\section{Private practices}

There were far fewer private practices in rural NSW; the vast majority were concentrated in the city (Figure 1). In Sydney, people in SEIFAs 1 and 5-8 were more likely to live greater than $2.5 \mathrm{~km}$ from a private dental practice (Figure 4). Further analysis of the distribution by SEIFA found that SEIFAs 1 and $6-8$ had the highest proportion of people living greater than $1.0 \mathrm{~km}$ from a private dental practice in the city (Figure 5). The density of private dental practices increased closer to the centre of the city (Figure 1).

\section{Further distributional analyses}

Sydney has a high population density and the majority of residents living in the city belonged to the least disadvantaged groups (SEIFA 8, 9, 10), while the minority were from the most disadvantaged groups (SEIFA 1, 2, 3). Figure 6 shows the density of private practices across Sydney. There was also a very high density of public dentists in the city. Figure 7 shows the relative density of public dental practices across NSW. Coverage of metropolitan Sydney by the "catchment zones" is dense and even. 


\section{Discussion}

Despite the reduction in dental decay in children and tooth loss in adults, oral diseases and disorders remain prevalent and a substantial burden in the Australian population. ${ }^{8}$ Accessing health care is not equal across the population ${ }^{15}$ and this is reflected in accessing oral health care in Australia. $^{7}$

The overall findings of this study demonstrate that the distribution of public and private dental practices does not entirely reflect the population characteristics and the burden of oral health diseases. The drivers of economic sustainability complicate the picture of clinical distribution, especially in private practice. In general, private dental practices in Sydney were distributed according to population density and income distribution.

An uneven distribution of dental practices relative to population can also be seen in other countries. A similar situation to NSW is found in Ohio in terms of the distribution of private dentists. ${ }^{16}$ Geographic information system research using spatial analysis was used to explore access to community-based oral health care services in Manhattan and the Bronx for adults aged 65 years and over by race/ ethnicity and poverty status. The study revealed that race/ ethnicity and poverty status co-occurs spatially among seniors in the two areas, with poorer and minority ethnic groups having less access to oral health services. ${ }^{17}$ Location-based accessibility to dental services was also assessed using the spatial approach, in a second study from Ohio, again finding similar distribution patterns as the current study. ${ }^{1}$ Spatial analysis has also been used to assess the distribution of fixed public dental practices in three Australian states (Western Australia, Queensland and Victoria) by CDs and socioeconomic status and private practices in Western Australia, and these studies found similar distribution patterns to the present study. ${ }^{18,19}$

It is known that the locations of private dental practices are driven by market forces and economy. ${ }^{20}$ Private dental services cannot be sustained in many rural and remote areas in part due to lack of dentists, high costs and low population density. These communities are reliant on state governments to fund or provide dental health services. Public dental practices are widely scattered in rural NSW. ${ }^{21-24}$ This study extended on these findings to also report a gradient of accessibility based on socioeconomic status: the greatest numbers of those who reside outside $50 \mathrm{~km}$ from a public dental practice were from lower socioeconomic communities. These findings confirm the situation where people from lower socioeconomic backgrounds in rural areas carry a higher burden of oral disease but have less access to dental care compared to higher socioeconomic groups; this may contribute to widening oral health inequalities among Australians. ${ }^{6,24-26}$ These results also agree with Susi and Mascarenhas ${ }^{16}$ findings that socioeconomic and access disparities are obvious in rural areas.
Most of the wealthier residents in this study (SEIFA 8, 9, 10) lived in the city, where the majority of private dental practices were also located. This finding supports previous research that per capita income is a good predictor of dentists' location in the private sector. ${ }^{27,28}$ With private practice remuneration being a core of the small business free market economic model of private dental practice this is not an unreasonable outcome. The number of dental clinicians per practice was not investigated in the study but the effects of workforce shortage and maldistribution are likely to magnify the results of this study, as the shortage of workforce is mainly experienced by the public sector and in rural areas.

\section{Conclusion}

The distribution of public and private dental practices did not entirely reflect the population characteristics and the burden of oral health diseases. The findings of this study can contribute to policy makers' determination of areas where additional resources are required and areas where incentive programs can be created that will attract dentists to rural and remote areas. The results can inform decisions to determine practice locations and identify such subgroups in the population that need significant attention for public health initiatives, reflecting the population characteristics and the burden of oral diseases. This will be a foundation that will help narrow the gap of inequalities and inequities in oral health care services in the Australian population.

\section{Acknowledgment}

The authors would like to thank the Centre for Oral Health Strategy NSW for assistance with the project, and specifically John Skinner for his assistance in the development of this study.

\section{References}

1. Horner MW, Mascarenhas AK. Analyzing location-based accessibility to dental services: an Ohio case study. $J$ Public Health Dent 2007; 67(2): 113-8. doi:10.1111/j.17527325.2007.00027.x

2. Cromley EK, McLafferty SL. GIS and Public Health. New York: Guilford Press; 2002.

3. Nykiforuk CI, Flaman LM. Geographic information systems (GIS) for Health Promotion and Public Health: a review. Health Promot Pract 2011; 12(1): 63-73. doi:10.1177/ 1524839909334624

4. McLafferty SL. GIS and health care. Annu Rev Public Health 2003; 24: 25-42. doi:10.1146/annurev. publhealth.24.012902.141012

5. Phillips RL Jr, Kinman EL, Schintzer PG, Lindbloom EJ, Ewigman B. Using geographic information systems to understand health care access. Arch Fam Med 2000; 9(10): 971-8. doi:10.1001/archfami.9.10.971

6. Spencer AJ. Narrowing the inequality gap in oral health and dental care in Australia. University of Sydney: Australian Health Policy Institute; 2004. 
7. Schwarz E. Access to oral health care - an Australian perspective. Community Dent Oral Epidemiol 2006; 34(3): 225-31. doi:10.1111/j.1600-0528.2006.00301.x

8. Oral health of Australians. In: National Planning for oral health improvement: Final report. Adelaide: South Australian Department of Human Services; 2001

9. Australian Bureau of Statistics. Census: for a brighter future. Available at: http://www.abs.gov.au/websitedbs/censushome. nsf/home/Census (Cited 21 June 2011).

10. Australian Bureau of Statistics. Census Dictionary Australia (Reissue). Catalogue No. 2901.0.2006. Canberra: ABS; 2006.

11. Australian Bureau of Statistics. Socio-Economic Indexes for Areas. Available at: http://www.abs.gov.au/websitedbs/cen sushome.nsf/home/seifa (Cited 31 January 2014).

12. Almado H, Kruger E, Tennant M. Application of spatial analysis technology to planning access to oral health care for at-risk populations in Australian capital cities. Aust J Primary Health, In press.

13. Phibbs CS, Luft HS. Correlation of travel time on roads versus straight line distance. Med Care Res Rev 1995; 52(4): 532-42. doi: $10.1177 / 107755879505200406$

14. Tennant M, Kruger E, Shiyha J. Dentist-to-population and practice-to-population ratios: in a shortage environment with gross mal-distribution what should rural and remote communities focus their attention on? Rural Remote Health 2013; 13(4): 2518.

15. Public Health Division. The health of the people of New South Wales - Report of the Chief Health Officer. Sydney; NSW Department of Health; 2004.

16. Susi L, Mascarenhas AK. Using a geographical information system to map the distribution of dentists in Ohio. J Am Dent Assoc 2002; 133(5): 636-42. doi:10.14219/jada.archive.2002.0239

17. Borrell LN, Northridge ME, Miller DB, Golembeski CA, Spielman SE, Sclar ED et al. Oral health and health care for older adults: a spatial approach for addressing disparities and planning services. Spec Care Dentist 2006; 26(6): 252-6. doi:10.1111/ j.1754-4505.2006.tb01663.x

18. Perera I, Kruger E, Tennant M. Rural public dental clinic distribution in three states of Australia: using spatial analysis to inform management and planning of services. Asia Pac J Health Management 2010; 5(1): 40-6.
19. Kruger E, Tennant M, George R. Application of geographic information systems to the analysis of private dental practices distribution in Western Australia. Rural Remote Health 2011; 11(3): 1736

20. Leake JL, Birch S. Public policy and the market for dental services. Community Dent Oral Epidemiol 2008; 36(4): 287-95. doi:10.1111/j.1600-0528.2008.00438.x

21. Teusner DN, Spencer AJ. Dental Labour Force, Australia 2000. Dental Statistics and Research Series No. 28. Cat. no. DEN 116. Canberra: Australian Institute of Health and Welfare; 2003.

22. Teusner DN, Chrisopoulos S, Brennan DS. Geographic distribution of the Australian dental labour force, 2003. Dental Statistics and Research Series No. 37. Cat. no. DEN 168. Canberra: Australian Institute of Health and Welfare; 2007.

23. Chrisopoulos S, Nguyen T. Trends in the Australian dental labour force, 2000 to 2009: Dental labour force collection, 2009. Dental Statistics and Research Series No. 61. Cat. no. DEN 218. Canberra: Australian Institute of Health and Welfare; 2012.

24. Slade GD, Spencer AJ, Roberts-Thomson K, eds. Australia's dental generations: the National Survey of Adult Oral Health 2004-06. AIHW cat. no. DEN 165. Canberra: AIHW; 2007.

25. Healthy Mouths, Healthy Lives. Australia's National Oral Health Plan 2004-2013. National Advisory Committee on Oral Health, South Australian Department of Health: Adelaide; 2004.

26. Rural Dental Action Group. Dental Health Survey 2006. Available at: http://www.ncoss.org.au/bookshelf/health/ submissions/RDAG\%20summary\%202006.pdf (Cited 19 December 2013).

27. Beazoglou TJ, Crakes GM, Doherty NJ, Heffley DR. Determinants of dentists' geographic distribution. J Dent Educ 1992; 56(11): 735-40.

28. Bailit HL, Beazoglou TJ. State financing of dental education: impact on supply of dentists. J Dent Educ 2003; 67(12): 1278-85. 